\title{
Effects of Different Convection Models Upon the High-Latitude Ionosphere
}

\author{
C. E. RASMUSSEN, R. W. SCHUNK, AND J. J. SOJKA
}

Center for Atmospheric and Space Sciences, Utah State University, Logan

\begin{abstract}
It is well known that convection electric fields have an important effect on the ionosphere at high latitudes and that a quantitative understanding of their effect requires a knowledge of plasma convection over the entire high-latitude region. Two empirical models of plasma convection that have been proposed for use in studying the ionosphere are the Volland and Heelis models. Both of these models provide a similar description of two-celled ionospheric convection, but they differ in several ways, in particular, in the manner in which plasma flows over the central polar cap and near the polar cap boundary. In order to obtain a better understanding of the way in which these two models affect the ionosphere, two separate runs of our high-latitude, time-dependent ionospheric model were made, with only the convection models distinguishing the two runs. It was found that the two models lead to differences in the ionosphere but often the differences are subtle and are swamped by universal time effects. The most notable differences are in predictions of the height of the $F_{2}$ peak and in the ion temperature, particularly along the evening polar cap boundary and in the cusp region. For these two parameters, the differences caused by the two different convection models dominate the universal time effects. One question that arises is whether one could examine measurements of plasma density and temperature and determine which of the two convection models most accurately represents actual ionospheric convection. Unfortunately, it is expected that when the effects of other ionospheric inputs are considered, such as the neutral wind, the uncertainties are sufficiently large that the characteristic differences between the Volland and Heelis convection models cannot be clearly identified in an examination of plasma density and temperature measurements.
\end{abstract}

\section{INTRODUCTION}

During the last decade, a major effort has been devoted to studying the effect that magnetospheric electric fields have on the high-latitude ionosphere and neutral atmosphere. Very early, it became apparent that a quantitative understanding of the effect of magnetospheric electric fields could not be obtained without a knowledge of the plasma convection pattern. Experimentally, the convection pattern and associated electric fields have been studied by a variety of techniques, including satelliteand rocket-borne probes [Heppner, 1972, 1977; Maynard, 1974; Kelley et al., 1975; Heelis et al., 1976], balloon-borne probes [Mozer and Lucht, 1974], observations of the drift of clouds of ionized barium [Haerendel et al., 1967], incoherent scatter observations of the drift of the $F$ region plasma [Doupnik et al., 1972; Evans et al., 1980; Foster et al., 1981], and coherent scatter observations of the drift of $E$ region irregularities [Greenwald et al., 1978].

All of the measurement techniques described above provide information on only a limited spatial region at any instant of time, requiring that the overall pattern of high-latitude electric fields be synthesized by combining observations made at a variety of places and times. Since individual measurements have shown the convection pattern to be both structured and highly variable, the synthesis of measurements made at different places and times leads to "average" rather than "instantaneous" convection patterns. Nevertheless, these average convection patterns clearly show that most of the time plasma convection exhibits a two-celled structure with antisunward flow over the polar cap and return flow at lower latitudes.

In an effort to describe plasma convection on a global scale, several empirical models have been developed. A simplified,

\section{c}

Paper number 5 A 8870 .
OI 148 - 0227 .

48-0227/86/005A-8870\$05.00 analytical model of the ionospheric electric field has been presented by Volland [1975]. This model lacks well-known details of ionospheric convection, such as the dayside throat and the Harang discontinuity, but because of its analytical nature it has been used extensively in high-latitude models [e.g., Sojka et al., 1981]. More recently, empirical models have been provided by Heppner [1977], based upon OGO 6 traverses of the polar cap, and by Foster [1983], based upon Chatanika incoherent-scatter observations. Unfortunately, these later convection models are not entirely suited for modeling the high-latitude ionosphere and thermosphere because they are not analytic representations. A model provided by Heelis et al. [1982], being built upon analytic functions, overcomes this limitation, and as it contains many more free parameters than the original Volland model, allows a better description of the dayside throat and the night sector flow reversal region.

Both the Volland and Heelis models provide a similar description of two-celled convection, and in fact the Volland formulation is contained as a subset within the set of possible "Heelis" plasma flow patterns. However, the additional features introduced by Heelis et al. [1982], including the dayside throat, the Harang discontinuity, and nonuniform polar cap electric fields, are the characteristic features of this model. As a consequence, ionospheric and thermospheric modelers frequently contrast the two types of convection patterns simply by calling them "Volland" and "Heelis" patterns. For convenience, we will adopt this convention in our paper.

The real question is whether or not the additional features provided by the Heelis model are needed in ionospheric and thermospheric modeling. From plasma convection data alone, there is no clear reason for selecting one of the models as a better description of ionospheric convection [Sojka and Schunk, 1986]. However, it is expected that the two different convection models will produce different ionospheric signatures. Just how much and in what way the ionosphere is affected by these two convection models (Volland and Heelis) is the topic of this 
paper. Also considered is the possibility of determining which model more accurately represents ionospheric convection by using ion density and temperature data in addition to the velocity data.

The study described in this paper was conducted by first selecting the parameters needed to describe the two convection models. It was required that both models give similar descriptions of ionospheric convection, while preserving the distinctive differences between the two models, notably in the different descriptions of plasma flow in the regions of the dayside throat and the polar cap. A description of the parameters which determine the two convection models and the values which were selected for this study are given in section 2 . In section 3 , the high-latitude ionospheric model is briefly discussed along with the required inputs to the model. In sections 4 and 5, the results of the two high-latitude ionospheric model runs are presented and contrasted. A discussion and summary are presented in section 6 .

\section{Convection Models}

Our high-latitude ionospheric model requires a plasma convection pattern on a global scale. Both the Volland and Heelis models provide this pattern after several input parameters are specified. In this section, the selected input parameters for the two models are given and the resulting convection patterns are shown.

Both models require similar inputs, such as the total cross-tail electric potential, the diameter of the polar cap, and the potential falloff rate outside the polar cap. However, due to its added complexity, the Heelis model requires more parameters to completely specify the model. The values for these parameters are given in Table 1, where the parameter symbols are identical to those adopted by Heelis et al. [1982]. Additionally, the convection pattern is displaced $2^{\circ}$ from the magnetic pole in the antisunward direction.

The parameters for the Volland model were selected so that both models give a similar description of ionospheric convection while preserving the features that are characteristic of each model. For instance, the Volland model has the same cross-tail potential of $75 \mathrm{kV}$ as the Heelis model, as well as the same rate of falloff of the potential with latitude outside of the polar cap $\left(r_{1}=\right.$ -4 in the notation of Heelis et al. [1982]). Although the two models handle the specification of the potentials near the polar cap boundary differently, the polar cap radius of $18^{\circ}$ selected for the Volland model is similar to the parameters selected for the Heelis model. In addition, we have modified the 1975 Volland model somewhat. An asymmetry between the dawn $(30 \mathrm{kV})$ and dusk $(-45 \mathrm{kV})$ regions was created and the potential pattern was displaced $2^{\circ}$ from the magnetic pole in the antisunward direction.

In the top portion of Figure 1 the ionospheric electricpotential distribution is shown for the Heelis model (left-hand side) and for the Volland model (right-hand side). As noted above, both patterns are shifted slightly antisunward from the magnetic pole. Also, both models were chosen such that there is a slight asymmetry between the dawn and dusk cells. This enables a comparison of both low- and high-convection velocities to be made between the two models. There are also important differences between the two potential patterns. One of the major differences is that for the Heelis model, the maximum potential in the convection cells is distributed along a line, whereas for the Volland model it occurs at a point. Further-
TABLE 1. Parameters for the Heelis Convection Model

\begin{tabular}{cc}
\hline Parameter & Value \\
\hline$\phi_{d}$ & 0 \\
$\phi_{d}^{+}$ & 1 \\
$\phi_{d}^{-}$ & 3 \\
$\phi_{n}$ & 12 \\
$\phi_{n}^{+}$ & 3 \\
$\phi_{n}^{-}$ & 1 \\
$\theta_{c}$ & 14 \\
$\theta_{1}$ & 19 \\
$\theta_{0}$ & 18 \\
$\theta_{2}$ & 17 \\
$\psi_{m}$ & 30 \\
$\psi_{e}$ & -45 \\
$r_{1}$ & -4 \\
$r_{2}$ & 2 \\
\hline
\end{tabular}

more, for the Heelis model the electric field in the polar cap is not uniform, in contrast to that for the simple Volland model. Also, note the presence of the restricted throatlike feature near the zero potential contour in the dayside Heelis model. The Volland model does not have this feature, nor does it have as marked a Harang-discontinuity-like feature near 0100 as the Heelis model does.

As the plasma $\mathbf{E} \times \mathbf{B}$ drifts in response to the presence of the electric fields described by the potential patterns in the top portion of Figure 1, substantial horizontal velocities are achieved. The magnitude of the horizontal velocities for the Heelis model (left-hand side) and for the Volland model (righthand side) are shown in the middle portion of Figure 1. Both models give maximum speeds near $800 \mathrm{~m} / \mathrm{s}$ in the dawn sector and $1200 \mathrm{~m} / \mathrm{s}$ in the dusk sector. However, the regions of high speed for the Heelis model are spread relatively evenly in MLT, while the same regions for the Volland model are concentrated about 0600 and 1800 MLT. Also, regions of high speed are found in the polar cap for the Heelis model, but not the Volland.

The plasma undergoes vertical motion in response to the convection electric field as well. Contours of the vertical (with respect to the earth's gravitational field) component of the $\mathbf{E} \times \mathbf{B}$ drift are shown in the bottom portion of Figure 1. In contrast to the horizontal speeds, the magnitudes of the vertical drifts are not similar for the two models. The Heelis model (left-hand side) predicts much higher drifts, with an upward drift of greater than $135 \mathrm{~m} / \mathrm{s}$ in the noon sector and a downward drift of greater than $165 \mathrm{~m} / \mathrm{s}$ in the midnight sector. The high electric fields in the throat and the Harang discontinuity are responsible for the much larger vertical drifts in the Heelis model.

Both of these convection models describe two-cell convection with predominantly antisunward flow over the polar cap and return flow at lower latitudes. This can be seen in Figure 2, where plasma streamlines are shown for the Heelis (left-hand side) and Volland (right-hand side) models in a quasi-inertial reference frame. These patterns do not vary with time. The large solid circles indicate the start of each plasma trajectory and thereafter the small solid circles indicate hourly intervals. Although not all the convection paths are shown in Figure 2, the ones plotted clearly demarcate the different regions of plasma convection. The plasma near trajectory 1 nearly corotates with the earth at all local times, while plasma stagnation is evident in the evening sector for trajectory 2 , and even more dramaticaily for trajectory 3 at the point where the flow turns westward after 

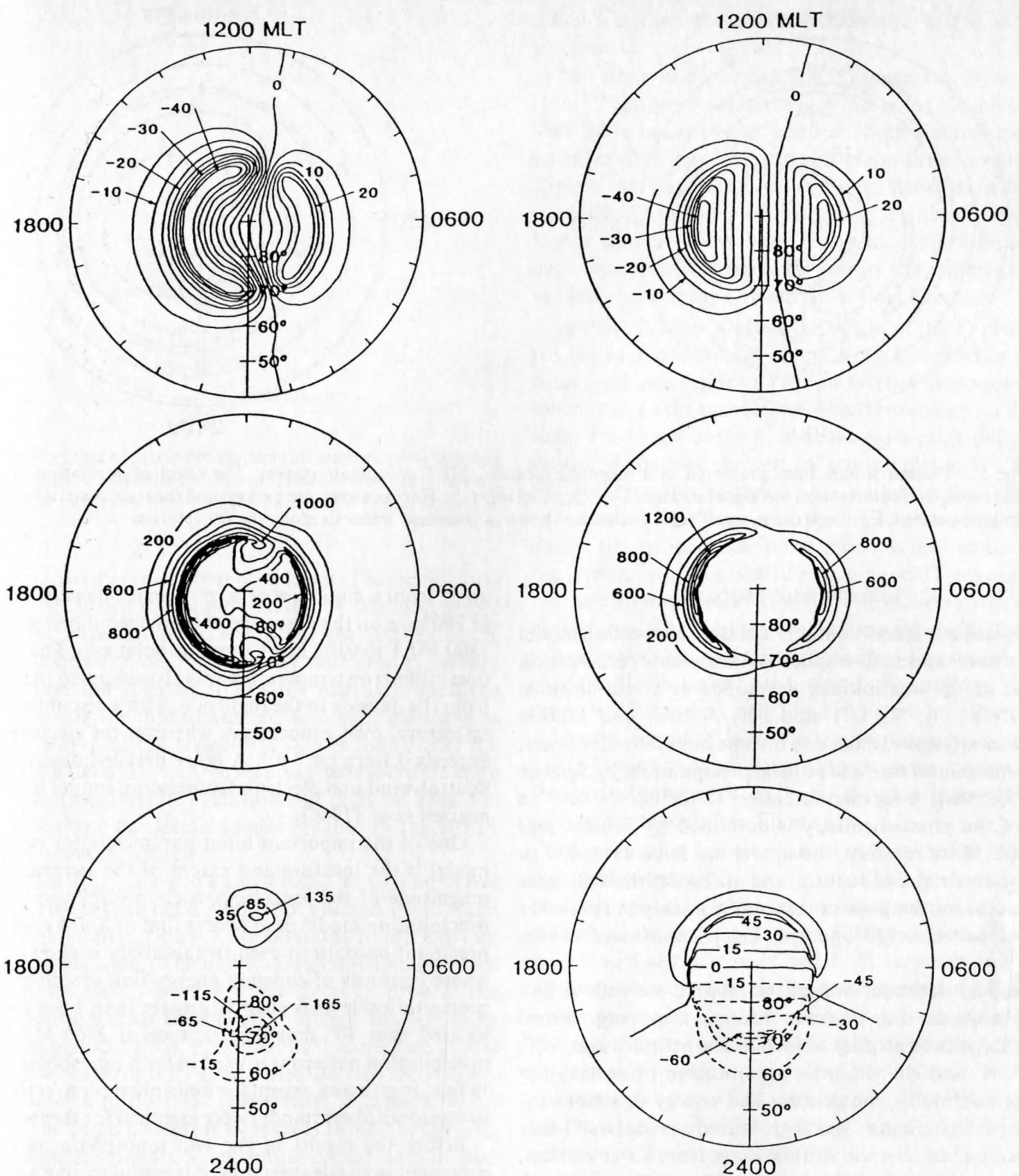

Fig. 1. Heelis (left panel) and Volland (right panel) magnetospheric convection patterns. The top panels show the electrostatic potential distribution in a magnetic latitude, MLT coordinate system. The middle panels show the corresponding horizontal speed distributions in the same frame. The speeds are in meters per second. The bottom panels show the corresponding vertical drifts. The drifts are in meters per second with solid contours for upward drifts and dashed contours for downward drifts.

1800 MLT. Stagnation occurs wherever the $\mathbf{E} \times \mathbf{B}$ velocity opposes and is roughly equal to the corotation velocity. Thus, Hagnation occurs in the evening sector, while in the morning rector the $\mathbf{E} \times \mathbf{B}$ velocity acts to speed up the plasma. Trajectories 5 and 6 outline the dusk and dawn convection cells of clockwise and counterclockwise rotation, respectively.

Distinctive features of the Heelis and Volland models can be seen in Figure 2. A "bananalike" pattern is formed by the trajectories contained within the border of trajectory 5 for the Heelis model. This pattern is formed, principally, because at high latitudes Heelis trajectories tend to follow contours of Constant latitude, while the Volland trajectories do not. This endency is also clearly evident within the polar cap, where plasma flux tubes following the Heelis trajectories flow eastward along contours of constant latitude while the flux tubes following the Volland trajectories flow predominantly antisunward across the polar cap. Another difference between the two models is the location of the turning point of trajectory 3 , where the plasma flow changes from an eastward to a westward direction. This turning point occurs near 1900 MLT for the Volland model, but not until 2200 MLT for the Heelis model. Since the location of this turning point is connected with the formation of the mid-latitude trough (at least in the summer hemisphere) [Rasmussen et al., 1986], it is expected that the electron densities obtained for the two convection models will differ somewhat in the evening sector. 

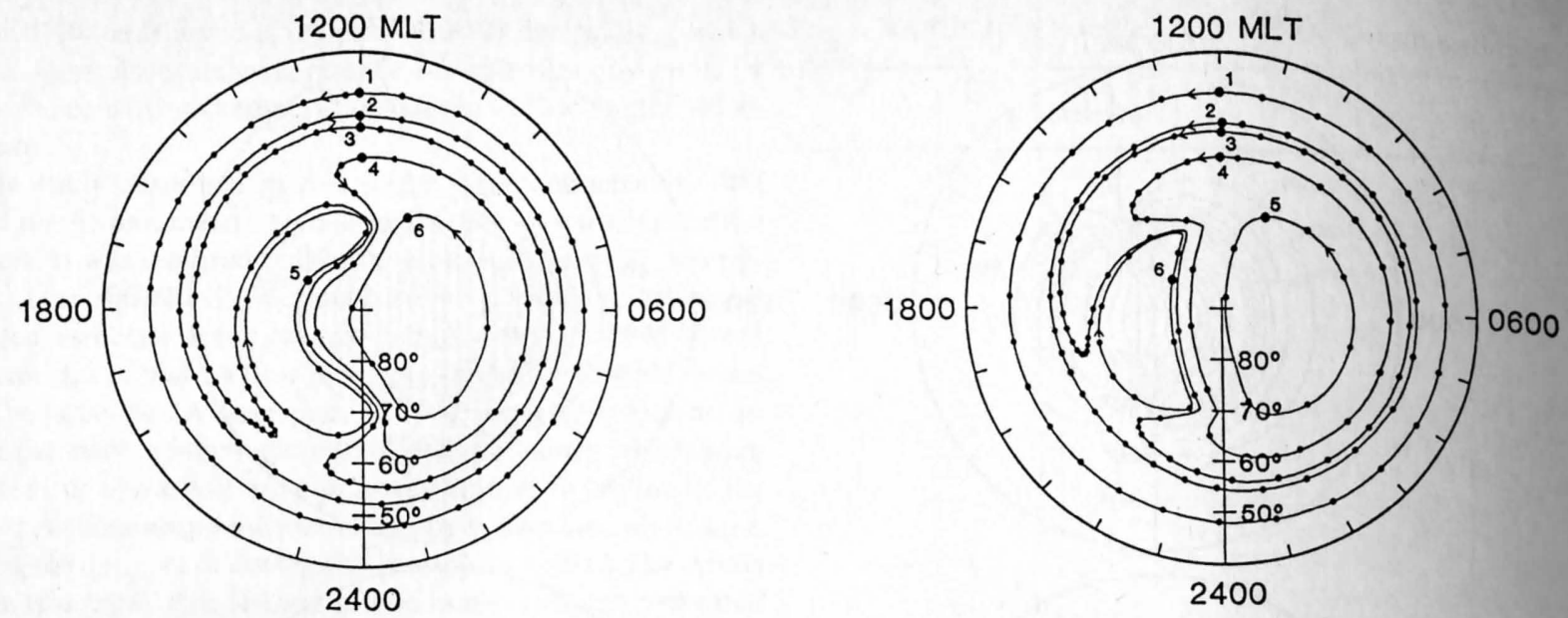

Fig. 2. Plasma stream lines presented in a magnetic latitude, MLT coordinate system. The effect of corotation upon magnetospheric convection has been included. The left panel is for the Heelis convection pattern and the right panel is for the Volland pattern. For both cases, small solid circles are shown at one-hour intervals along the trajectories.

\section{IONOSPHERIC MODEL}

Our high-latitude model contains a plasma convection model (described above) and an ionospheric-atmospheric composition model. The model was initially developed as a mid-latitude, multi-ion $\left(\mathrm{NO}^{+}, \mathrm{O}_{2}^{+}, \mathrm{N}_{2}^{+}, \mathrm{O}^{+}\right)$model by Schunk and Walker [1973]. The model was extended to include high-latitude effects, such as plasma convection and auroral precipitation, by Schunk et al. [1975, 1976]. A further extension to include $\mathrm{N}^{+}$and an updating of the photochemistry is described by Schunk and Raitt [1980]. More recently, the model has been extended to include ion thermal conduction and diffusion-thermal heat flow, so that the ion temperature is now rigorously calculated at all altitudes between 120 and $800 \mathrm{~km}$ [Schunk and Sojka, 1982a].

With the high-latitude ionospheric model, we follow flux tubes of plasma as they convect through a moving neutral atmosphere. Altitude profiles of the ion temperature and $\mathrm{NO}^{+}$, $\mathrm{O}_{2}^{+}, \mathrm{N}_{2}^{+}, \mathrm{O}^{+}, \mathrm{N}^{+}$and $\mathrm{He}^{+}$densities are obtained by solving the appropriate continuity, momentum and energy equations including numerous middle- and high-latitude processes. These equations are solved over the altitude range from 120 to $800 \mathrm{~km}$, with chemical equilibrium at $120 \mathrm{~km}$ and zero plasma outflow at $800 \mathrm{~km}$ being the lower and upper boundary conditions, respectively. To include universal time effects, each trajectory is followed 12 times, with the start time separated by 2 -hour UT intervals.

A number of parameters are required as inputs to this model. Ionization is produced through three mechanisms: EUV solar radiation, resonantly scattered radiation and auroral precipitation. Each of these ionization sources needs to be specified. The composition of the neutral atmosphere and its temperature are required and, in addition, models of the thermospheric wind, and electron temperature are needed.

The model input parameters that were selected for this study are now discussed. A winter day (with active solar conditions) was selected because the winter ionosphere is subject to more variability and, thus, it is expected that any differences due to the different convection models would be more readily apparent. The mass spectrometer/incoherent scatter (MSIS) model was used to describe the neutral atmosphere, while the neutral wind was assumed to vary smoothly with the solar zenith angle from a minimum of $30 \mathrm{~m} / \mathrm{s}$ on the dayside to a maximum of $200 \mathrm{~m} / \mathrm{s}$ on the nightside, with the wind being directed from 1300 MLT to 0100 MLT over the polar cap. The diurnal variation in electron temperature was also assumed to vary smoothly from the dayside to the nightside, with a discontinuous jump to an auroral oval temperature wherever the electron energy flux exceeds $0.1 \mathrm{erg} \mathrm{cm}^{-2} \mathrm{~s}^{-1}$. A more detailed description of these neutral wind and electron temperature inputs is given by Rasmussen et al. [1986].

One of the important input parameters for our ionospheric model is the location and extent of the auroral oval and the magnitude of the ionizing-particle precipitation. The particle precipitation model used here is that of Spiro et al. [1982]. The precipitation pattern used in this study is shown in Figure 3, where contours of constant energy flux are plotted. The peak precipitation level is slightly greater than $1 \mathrm{erg} \mathrm{cm}^{-2} \mathrm{~s}^{-1}$ and is located near $70^{\circ}$ magnetic latitude at $2400 \mathrm{MLT}$. The same precipitation pattern was used in both ionospheric model runs. In fact, in all cases, except for ionospheric convection, the inputs to our ionospheric model were identical for the two model runs.

Before the results of the two ionospheric model runs are presented in the next section, it is useful to give a description of the magnetic-dipole reference frame that is used internally in the model and also to plot much of the data. The magnetic frame is defined by a dipole magnetic field whose pole is located at $78.6^{\circ}$ $\mathrm{N},-69.8^{\circ} \mathrm{E}$ in geographic coordinates. This location is based upon the dipole component of the Mead [1970] magnetic reference field. In this frame we use dipole latitude and magnetic local time (MLT) as the magnetic coordinates.

\section{Modeled $F$ Region PaRAmeters}

To compare the density signatures associated with the Heelis and Volland convection patterns, it is instructive to look at some of the important ionospheric parameters, such as the electron density at the $F_{2}$ peak $\left(N_{m} F_{2}\right)$, the altitude of the $F_{2}$ peak $\left(h_{m} F_{2}\right)$, and the electron density $\left(N_{e}\right)$ at an altitude well above the $F_{2}$ peak. It is also important to consider the ion temperature $\left(T_{i}\right)$ and the molecular-atomic ion transition height. This is done in this section.

First, however, it is noted that in order to obtain the plots shown in this section, it was necessary to follow the plasma 




Fig. 3. The energy flux of precipitating auroral electrons presented in a magnetic latitude, MLT coordinate system. The contours are labeled in ${ }_{\text {trg }} \mathrm{cm}^{-2} \mathrm{~s}^{-1}$. The pattern is based on the Spiro et al. [1982] empirical nodel.

around each trajectory for two complete loops. The second loop was necessary because it was found that it took one loop before information about the initial conditions was lost. At the starting point of each trajectory, we obtain steady state density profiles for the flux tube and then we follow the plasma around the trajectory, allowing the input parameters to vary naturally as the flux tube traverses the trajectory. It was found that the plasma is not in a steady state in the regions where there are large upward or downward drifts, even in sunlit regions. This was especially critical for the Heelis model because of the strong upward drifts in the throat region.

Color plots of $N_{m} F_{2}$ are shown in Plate 1 at two universal times for the Heelis (left-hand side) and Volland (right-hand side) convection models. (Plate 1 can be found in the separate color section in this issue.) The universal times ( 0400 top panel and 1600 bottom panel) were selected so as to provide the greatest difference in solar zenith or UT effects. In comparing the left- and right-hand sides, it is obvious that the two model runs are notable more for their similarities than for their differences. For instance, in the 0400 comparison (top panel) both models show the same general features: (1) similar regions of high density due to solar EUV ionization on the dayside and auroral precipitation in the auroral oval; and (2) similar troughs occurring at mid-latitudes in the dawn and dusk sectors with the lowest densities reached at $0700 \mathrm{MLT}$. Another notable similarity is that both models show plasma from the evening trough being convected into the polar cap. This is in contrast to the 1600 UT comparison, where high densities are convected into the polar cap, forming a "tongue of ionization." Another similarity between the two models is that the lowest-density troughs and the highest-density peaks occur at the same universal time $(1600)$. This happens because the plasma forming the deep trough at 1600 UT was in daylight 12 hours earlier (0400 UT), when the terminator was at its furthest sunward location.

Some subtle differences are noted in the ionospheric signatures for the Heelis and Volland convection models. The plasma that is transported into the polar cap from the evening sector trough (top panel) shows the characteristic shape of trajectory 3 plotted in Figure 2 for each convection model. The bottom Panel shows evidence of a narrow, throatlike feature for the Heelis run, but not for the Volland run. However, it is important to note that these differences (due to the convection models) are much less than the differences caused by the motion of the terminator.

The electron density at 784 kilometers is shown in Plate 2. (Plate 2 can be found in the separate color section in this issue.) This plate has the same features (both similarities and differences) as noted for Plate 1 . Some of the differences in density are slightly more accentuated, with peak densities in the polar cap (at $1600 \mathrm{UT}$, lower panel) differing by about $50 \%$ due to the higher upward drifts in the Heelis model (see Figure 1). However, again, the differences due to the different convection models are swamped by universal time effects.

In Plate 3, color plots of the height of the $F_{2}$ peak are shown for the two model runs. (Plate 3 can be found in the separate color section in this issue.) In contrast to the two previous plates, effects due to the movement of the terminator no longer dominate. The height of the $F_{2}$ peak $\left(h_{m} F_{2}\right)$ is principally affected by vertical drifts, and the vertical motion due to $\mathbf{E} \times \mathbf{B}$ drifts does not depend upon universal time. Although the vertical motion associated with the neutral wind has a universal time dependence, this dependence in our model is limited to regions near the terminator. This lack of a dominant UT dependence allows for the differences due to the two convection models to be more clearly seen. The Heelis model leads to substantially higher $h_{m} F_{2}$ values in the region of the throat where plasma enters the polar cap, the Heelis model predicting $h_{m} F_{2}$ altitudes $50 \mathrm{~km}$ higher than the Volland model. The Heelis model also predicts substantially lower $h_{m} F_{2}$ altitudes as the plasma exits the polar cap. These findings are not surprising given the large differences in the vertical component of the $\mathbf{E} \times \mathbf{B}$ drifts obtained from the two convection models (see Figure 1).

An interesting feature is noted in Plate 3. The Heelis convection model leads to a narrow band of relatively high $h_{m} F_{2}$ values (in comparison to latitudes on either side), centered near $70^{\circ}$ magnetic latitude and between 1200 and 1800 MLT. The Volland model also has increased $h_{m} F_{2}$ values in this region, but they are not as dramatic and not as extended in MLT. This band is not created by high vertical drifts because there are none in this region (see Figure 1). However, there are high horizontal drifts in this location, which lead to elevated ion temperatures owing to ion-neutral frictional heating (Plate 4). Therefore, this region of high $h_{m} F_{2}$ values is caused by an increased recombination rate in the lower ionosphere due to the high ion temperatures. The increased recombination rate causes a decrease in density at lower altitudes (see Plate 1) and an increase in $h_{m} F_{2}$ [Schunk et al., 1975, 1976]. (Plate 4 can be found in the separate color section in this issue).

The ion temperatures, as seen in Plate 4 and noted above, increase by over a thousand degrees in this narrow latitude region. The ion heating is caused by high, zonal convection velocities. In the Volland model (right-hand side), this heating occurs in a relatively limited region, creating a hot spot [Schunk and Sojka, 1982b]. However, the Heelis model leads to ion heating over a much larger longitudinal region; in fact, it leads to fairly substantial heating around the entire polar cap boundary.

The transition altitude, where the transition from the dominance of molecular ions to the dominance of atomic ions occurs, is shown in Plate 5 in the same format as the previous color plates. (Plate 5 can be found in the separate color section in this issue.) This altitude is an important parameter in interpreting much of the data gathered by the incoherent-scatter radars, especially in determining ion temperatures. Similar to the $h_{m} F_{2}$ 
altitude, the Heelis model leads to an increased transition height in the throat region and in the latitudinal band where substantial ion heating occurs.

\section{RADAR Simulation}

In this section the altitude dependence of electron density is examined. The modeled densities are presented as if measured by an incoherent-scatter radar, that is, altitude profiles are plotted versus MLT for fixed locations in geographic coordinates. The temporal variation is obtained as the local time changes at the fixed (radar's) location. This is done to determine whether density data could be used in conjunction with drift velocity data in an effort to ascertain which convection model most closely represents actual ionospheric convection.

The longitudinal locations corresponding to three radar sites were chosen. The radars chosen were Chatanika $\left(213^{\circ} \mathrm{E}\right)$, Sondrestrom $\left(309^{\circ} \mathrm{E}\right)$, and the European Incoherent Scatter System (EISCAT) $\left(20^{\circ} \mathrm{E}\right)$. Although Millstone Hill could have been included, the longitude of Millstone Hill is quite close to that of Sondrestrom, so the model results are virtually the same for both locations. In Plate 6 electron densities are shown as a function of altitude and MLT at $70^{\circ}$ magnetic latitude for Sondrestrom (top), Chatanika (middle), and EISCAT (bottom). (Plate 6 can be found in the separate color section in this issue.) As above, the left panel shows the results using the Heelis convection model and the right panel is for the Volland model. A magnetic latitude of $70^{\circ}$ was chosen because this latitude is near the polar cap boundary where the plasma both enters (dayside) and leaves (nightside) the polar cap. Also, all three radars can reach, or nearly reach, this latitude.

One of the most noticeable features in Plate 6 is the presence of sharp discontinuities in the modeled results. Note, in particular, the lower-left plot where several marked changes in density occur with changing MLT near local noon. Most often, these changes are the result of crossing trajectory boundaries, marking plasma coming from different regions of the ionosphere. For instance, at $70^{\circ}$ magnetic latitude, trajectory 6 (see the left-hand side of Figure 2) is crossed near 1030 MLT, trajectory 4 near 1145 MLT, trajectory 3 near 1230 MLT, and trajectory 5 near 1300 MLT. The crossing of trajectory 3 is especially apparent, since it is this crossing that accounts for the lowest $N_{m} F_{2}$ values of the entire day in the lower left-hand plot. Note that this occurs near local noon when one might expect the $N_{m} F_{2}$ values to be highest. Looking at the upper-left plot, one no longer finds the lowest $N_{m} F_{2}$ values near local noon. This points out the strong UT (longitudinal) dependence of the ionosphere.

The crossing of trajectory 3 for the Volland model (see the right-hand side of Figure 2) does not occur until 1500 MLT. This trajectory crossing is noted by the sharp decrease in density at this local time in the middle-right and the lower-right plots. There is a predicted 2.5-hour time difference between the crossing of trajectory 3 for the two convection models. This is primarily an effect of the narrow-throat region of the Heelis model. Another effect of the Heelis model throat is the narrowing of the dayside peak densities, especially noticeable in the upper-left plot in comparison with the upper-right plot. The values of $h_{m} F_{2}$ tend to be higher near local noon for the Heelis convection model as well. Another noticeable difference between the two convection models is the relatively lower densities shortly after local midnight predicted in the Heelis model results.

\section{Discussion}

The purpose of this paper has been to determine the effects that different features of ionospheric convection have upon the high-latitude ionosphere. To achieve this end, we have run ou high-latitude ionospheric model two times, once using the Heelis convection model and once using the Volland convection model; all other model inputs were the same for the two model runs. The resulting ionospheric signatures were then compared with each other at two universal times. The output parameters compared were $N_{m} F_{2}, N_{e}$ near $800 \mathrm{~km}, h_{m} F_{2}$, the ion temperature and the molecular-atomic ion transition height. In general it was found that the ionosphere has a limited dependence upon the details of the convection model, at least for the convection models considered in this study. It was found that UT effects dominate the density signatures, although a close examination of densities at a given universal time reveals some distinct differences.

The principal effects of the different convection models were seen in the height of the $F_{2}$ peak and in the ion temperature. The height of the $F_{2}$ peak was predominantly affected by the vertical component of the $\mathbf{E} \times \mathbf{B}$ convection velocity, while the ion temperatures were mostly affected by the horizontal component. The Heelis model led to higher $h_{m} F_{2}$ values, by $50 \mathrm{~km}$, in the region where plasma is transported into the polar cap (in comparison to the Volland model) and lower $h_{m} F_{2}$ values in the region where plasma is transported out of the polar cap. Both convection models produced increased ion temperatures in a narrow latitudinal band, but the Heelis model predicted elevated ion temperatures over a much broader longitudinal range, including some ion heating over the entire circumference of the polar cap.

Although not directly pertaining to differences in the convection models, since both models showed this feature, it was seen that for certain locations of the terminator, plasma could be transported from the dusk trough into the polar cap. This is similar to the better-known occurrence of high-density plasma being transported into the polar cap and forming a "tongue of ionization."

Another goal of this study was to determine whether density data could be used in conjunction with drift velocity data in an effort to ascertain which of the two convection models most closely represents actual ionospheric convection. In particular, the diurnal variation in electron densities was examined at different geographic longitudes, corresponding to three radar sites. Although these results indicated that there are density signatures associated with the convection models, the interpretation of the radar data would be clouded by other variations. One of the most important is that ionospheric convection is often not sustained, varying markedly during storms and substorms. If the cross-tail potential were to change during the course of the data gathering period, it is not clear how this change would affect the Heelis or Volland signatures found in this study.

Furthermore, any temporal variation, or uncertainty, in the values of the "inputs" to the ionosphere would present difficulties. In this theoretical study, all inputs were obviously known and were either held fixed in time or only had a universal time dependence. In any actual experiment, this would most probably not be the case and any uncertainties in, say, auroral precipitation or the neutral wind would lead to uncertainties in the interpretation of the data. The neutral wind is especially important as it strongly affects $h_{m} F_{2}$, which is a distinguishing parameter of the two convection models.

In light of the above, it seems that it would be difficult to distinguish between the two convection models using just incoherent scatter radar data even if density and temperature data 
used to supplement the drift velocity data. However, if welis- or Volland-like features were to be found, it would be fe to say that the best place to look for them would be in the gion of the throat (near the cleft) and in the polar cap. Also, he parameters to look at would be those closely linked to the pivection velocity, such as the ion temperature and $h_{m} F_{2}$ as vell as the convection velocity itself. One would also want to ${ }_{100 k}$ for ionospheric features distinguishing trajectory crossings discussed in section 5), as these would contain information pertaining to the convection pattern.

Acknowledgments. This research was supported by AFOSR conret AFOSR-84-0029, NSF grant ATM-8417880, and NASA grant vAGW-77 to Utah State University. The computer modeling effort was wported by the National Center for Atmospheric Research, which is suppored by the National Science Foundation.

The Editor thanks J. Burch and R. W. Spiro for their assistance in evaluating this paper.

\section{REFERENCES}

Doupnik, J. R., P. M. Banks, M. J. Baron, C. L. Rino, and J. Petriceks, Direct measurements of plasma drift velocities at high magnetic latitudes, J. Geophys. Res., 77, 4268-4271, 1972.

Evans, J. V., J. M. Holt, W. L. Oliver, and R. H. Wand, Millstone Hill incoherent scatter observations of auroral convection over $60^{\circ} \leq \Lambda \leq$ $75^{\circ}, 2$, Initial results, J. Geophys. Res., 85, 41-54, 1980.

Foster, J. C., An empirical electric field model derived from Chatanika radar data, J. Geophys. Res., 88, 981-987, 1983.

Foster, J. C., J. R. Doupnik, and G. S. Stiles, Large scale patterns of auroral ionospheric convection observed with the Chatanika radar, $J$. Geophys. Res., 86, 11357-11371, 1981.

Greenwald, R. A., W. Weiss, E. Nielsen, and N. R. Thomson, STARE: A new radar auroral backscatter experiment in northern Scandinavia, Radio Sci., 13, 1021-1039, 1978.

Haerendel, G. R., R. Lust, and E. Reiger, Motion of artificial ion clouds in the upper atmosphere, Planet. Space Sci., 15, 1-18, 1967.

Heelis, R. A., W. B. Hanson, and J. L. Burch, Ion convection velocity reversals in the dayside cleft, J. Geophys. Res., 81, 3803-3809, 1976. Heelis, R. A., J. K. Lowell, and R. W. Spiro, A model of the highlatitude ionospheric convection pattern, J. Geophys. Res., 87, 63396345, 1982.

Heppner, J. P., Polar cap electric field distributions related to the interplanetary magnetic field direction, J. Geophys. Res., 77, 48774887, 1972.

Heppner, J. P., Empirical models of high-latitude electric fields, $J$. Geophys. Res., 82, 1115-1125, 1977.
Kelley, M. C., G. Haerendel, H. Kappler, F. S. Mozer, and U. V. Fahleson, Electric field measurements in a major magnetospheric substorm, J. Geophys. Res., 80, 3181-3195, 1975.

Maynard, N. C., Electric field measurements across the Harang discontinuity, J. Geophys. Res., 79, 4620-4631, 1974.

Mead, G. D., International geomagnetic reference field 1965.0 in dipole coordinates, J. Geophys. Res., 75, 4372-4374, 1970.

Mozer, F. S., and P. Lucht, The average auroral zone electric field, $J$. Geophys. Res., 79, 1001-1006, 1974.

Rasmussen, C. E., R. W. Schunk, J. J. Sojka, V. B. Wickwar, O. de la Beaujardiere, J. Foster, J. Holt, D. S. Evans, and E. Nielsen, Comparison of simultaneous Chatanika and Millstone Hill observations with ionospheric model predictions, J. Geophys. Res., in press, 1986.

Schunk, R. W., and W. J. Raitt, Atomic nitrogen and oxygen ions in the daytime high-latitude $F$ region, J. Geophys. Res., 85, 1255-1272, 1980.

Schunk, R. W., and J. J. Sojka, Ion temperature variations in the daytime high-latitude $F$ region, J. Geophys. Res., 87, 5169-5183, $1982 a$.

Schunk, R. W., and J. J. Sojka, Ionospheric hot spot at high latitudes, Geophys. Res. Lett., 9, 1045-1048, $1982 b$.

Schunk, R. W., and J. C. G. Walker, Theoretical ion densities in the lower ionosphere, Planet. Space Sci., 21, 1875-1896, 1973.

Schunk, R. W., W. J. Raitt, and P. M. Banks, Effect of electric fields on the daytime high-latitude $E$ and $F$ regions, J. Geophys. Res., 80, 3121-3130, 1975

Schunk, R. W., P. M. Banks, and W. J. Raitt, Effects of electric fields and other processes upon the nighttime high-latitude $F$ layer, J. Geophys. Res., 81, 3271-3282, 1976.

Sojka, J. J., and R. W. Schunk, Problems with deducing ionospheric plasma convection patterns, J. Geophys. Res., 91, 259-269, 1986.

Sojka, J. J., W. J. Raitt and R. W. Schunk, A theoretical study of the high-latitude winter $F$ region at solar minimum for low magnetic activity, J. Geophys. Res., 86, 609-621, 1981.

Spiro, R. W., P. H. Reiff, and L. J. Maher, Precipitation electron energy flux and auroral zone conductances-An empirical model, J. Geophys. Res., 87, 8215-8227, 1982.

Volland, H., Models of the global electric fields within the magnetosphere, Ann. Geophys., 31, 159-173, 1975.

C. E. Rasmussen, R. W. Schunk, and J. J. Sojka, Center for Atmospheric and Space Sciences, Utah State University, Logan, UT $84322-3400$.
(Received September 16, 1985; revised November 15, 1985; accepted November 15, 1985.) 